\title{
Characteristics of disability in activity of daily living in elderly people associated with locomotive disorders
}

\author{
Tsutomu Iwaya' ${ }^{1}$, Tokuhide Doi ${ }^{2}$, Atsushi Seichi ${ }^{3}$, Yuichi Hoshino ${ }^{4}$, Toru Ogata ${ }^{5}$ and Masami Akai ${ }^{6 *}$ (D)
}

\begin{abstract}
Background: Ageing is associated with a decline of motor function and ability to perform daily activities. Locomotive disorders are one of the major disorders resulting in adverse health condition in elderly people. Concept of Locomotive syndrome (LOS) was proposed to tackle the problems and prolong healthy life expectancy of people with locomotive disorders. To develop intervention strategy for LoS it is mandatory to investigate impairments, functional disabilities which people with locomotive disorder experience and to examine relationships among these parameters. For this purpose we have developed Geriatric Locomotive Function Scale-25 (GLFS-25). Though several physical performance tests were reported for identification or monitoring the severity of LoS, there are few studies reported on characteristics of disability which people with locomotive disorders experience. The aim of this study was to report the characteristics of ADL disabilities in elderly people with locomotive disorders in terms of numbers and degree of activity limitations.

Methods: We organized a cohort study and recruited 314 participants aged 65 years and over from five orthopedic clinics or nursing care facilities. This was a cross-sectional study to use the baseline data of such cohort. ADL disabilities were assessed using GLFS-25 scale arranging the GLFS-25 scores in ordinal levels using "R language" program. Numbers and degrees of activity limitations were determined and compared among the levels. Frequency of limitation in activities regarding social activity, housework, locomotion, mobility and self-care was compared among across the disability level.

Results: The GLFS-25 score was mathematically categorized into 7 levels. The number of activity limitations and the degrees of each activity limitation were significantly greater in high GLFS-25 levels than in low levels. Difficulties in mobility appeared in less severe level, difficulties in domestic and social life appeared in moderately severe level, and difficulties in self-care appeared in advanced level.
\end{abstract}

Conclusions: High GLFS-25 score represented high degree of disability on ADLs. Concordant increase of numbers of activity limitation and severity progression in activity limitation may contribute to progression of disability. Activity limitation may occur in the following order: sports activity, walking, transferring, and self-care.

Keywords: Locomotive syndrome, Geriatric Locomotive Function Scale-25, Activity limitation, Degree of disability, Disablement process

\footnotetext{
* Correspondence: akai-masami@iuhw.ac.jp; akai-masami@rehab.go.jp

${ }^{6}$ International University of Health and Welfare, 4F, Aoyama 1-Chome Tower,

1-3-3 Minami-Aoyama, Minato-ku, Tokyo 107-0062, Japan

Full list of author information is available at the end of the article
} 


\section{Background}

Aged society is accelerating rapidly in Japan. The total population of Japan was 127.11 million and the number of people aged 65 and over was 33.92 million as of October 1, 2015. The ratio of elderly people aged 65 and over was $26.7 \%$ [1] and it is expected to extend $30 \%$ in 2025 and reach $39.9 \%$ in 2060 [2]. The number of persons needing long-term care is increasing rapidly among elderly people, and the number of people more than 65 years old who are certified as requiring long-term care is 5.84 million (4.6\% of total population) at the end of fiscal year 2013 [3]. Many elderly people want to continue to live in their own houses and receive long term care [4]. As elderly people suffer from many diseases and experience disability in activities of daily living (ADL) due to declined functional limitations, it is necessary for health care professionals to provide interventions not only to control diseases, but to restore or maintain physical function and prevent or reduce disability.

Recently growing and important cause of the condition requiring Long Term Care Insurance (LTCI) support was locomotive organ disorders. The percentage of people utilizing LTCI services due to locomotive organ disorders (falls/fractures and joint disorders) has increased from $21.1 \%$ in 2010 [5] to $22.7 \%$ in 2013 [6].

The concept of "Locomotive syndrome (LoS)" was proposed to tackle such problems and to prolong healthy life expectancy of people with locomotive disorders. This syndrome refers to those elderly people who have come to need care services because of problems of the locomotive organs, or have risk conditions which may require them to have such services in the future $[7,8]$. The total number of individuals with LoS between the $40 \mathrm{~s}$ and $70 \mathrm{~s}$ in Japan was estimated to be approximately 7.5 million [9]. To prolong healthy life expectancy of the elderly people under the condition of LoS, it is necessary to develop intervention strategy for those who are currently healthy but at risk of disabling due to declining locomotor function [10] as well as for those who are disabled due to locomotor dysfunction and need nursing care. This concept does not depend upon traditional pathological basis. Actual pathological changes cover multiple organs derived from degenerative process. The Japanese Orthopedic Association started campaign to raise public awareness on interest in locomotive organ and facilitate early detection of those who are at risk of requiring support [11].

To identify people under the condition of LoS selfreported questionnaire on ADL disabilities (GLFS-25) [12] and motor function tests were developed [13]. Recent studies reported factors concerning pathology, impairments and functional limitations to identify people at risk of LoS. Osteoporosis, pain on low back, knee [14, 15], obesity [16], and spinal deformity [17] were reported to be risk factors for LoS. Several physical performance tests such as timed up and go test, one-leg standing time, back muscle strength, leg extension power, gait speed, grip power, and maximum stride, were proved to be valid for identification of $\operatorname{LoS}$ [18-20]. In all of these studies, LoS was detected by the Geriatric Locomotive Function Scale (GLFS) -25 total score.

A few studies were reported concerning types and degree of the ADL disabilities among elderly people with locomotive organ disorders. Tobimatsu [21] suggested that people developed difficulties in IADL items earlier than in ADL items. Moreover, mild difficulties in going up- and downstairs, walking briskly and long-distance walking (more than $2-3 \mathrm{~km}$ ), along with body pain (upper/lower extremities, back or neck), were experienced before the deficits in IADL or social functions were noted. Iwaya, Akai, and Doi [20] also reported that the number of difficult daily tasks increased in accordance with aggravation of locomotive disability.

To develop appropriate therapeutic regimen tailored to individuals with different severity of disability, it is necessary to investigate disablement process that include which factors are relevant to aggravation of disability and how the degree of disability progress. Severity of ADL disability is related to determining care needs of LTCI System. Support/care level of LTCI may differ from assigned care level based on the estimated care minutes due to personal particular needs combining living condition, family support, and other factors [22]. Considering the limitation of LTCI grading system, which is not purely limited in the degrees of support/care needs, it is necessary to investigate the degree of disability using measure that is valid for medical practice and research.

The Geriatric Locomotive Function Scale-25 (GLFS-25) was originally developed to screen the persons with locomotive dysfunction. GLFS-25 included 4 questions regarding pain, $19 \mathrm{ADL}$, and 2 anxiety (Table 1) [12]. Seichi et al. [9] reported age specific standard values on the GLFS-25 which was 4.4 in the $40 \mathrm{~s}, 5.5$ in the $50 \mathrm{~s}, 7.1$ in the $60 \mathrm{~s}$, and 12.7 in the 70 s.

The validity of GLFS-25 was confirmed by demonstrating a significant correlation and association of its score with the outcome of a series of functional performance tests $[18,20]$. Grade of physician-judged locomotive dysfunction was significantly related to GLFS-25 score [23].

According to these previous reports, we considered GLFS-25 was valid to investigate patterns of ADL disability in persons with locomotive disorders. We used 19 questions items regarding difficulties doing basic (mobility and personal care) and instrumental (household management and social life) ADLs to clarify the order of difficulties doing daily activities.

The aim of this study was to investigate the factors related to grades of ADL disability, and identify activity 
Table 1 Geriatric Locomotive Function Scale (GLFS) -25

\begin{tabular}{|c|c|c|}
\hline \multicolumn{3}{|l|}{ Please answer on your status over the last one month } \\
\hline Question items & Domain & Response options \\
\hline $\begin{array}{l}\text { 1. Did you have any pain (including numbness) in your neck or upper limbs } \\
\text { (shoulder, arm, or hand)? }\end{array}$ & pain & \multirow{4}{*}{$\begin{array}{l}\text { 0: no pain } \\
\text { 1: mild pain } \\
\text { 2: moderate pain } \\
\text { 3: considerable pain } \\
\text { 4: severe pain }\end{array}$} \\
\hline 2. Did you have any pain in your back, lower back or buttocks? & pain & \\
\hline $\begin{array}{l}\text { 3. Did you have any pain (including numbness) in your lower limbs } \\
\text { (hip, thigh, knee, calf, shin, ankle, or foot)? }\end{array}$ & pain & \\
\hline 4. To what extent has it been painful to move your body in daily life? & pain & \\
\hline 5. To what extent has it been difficult to get up from a bed or lie down? & mobility & \multirow{10}{*}{$\begin{array}{l}\text { 0: not difficult } \\
\text { 1: mildly difficult } \\
\text { 2: moderately difficult } \\
\text { 3: considerably difficult } \\
\text { 4: extremely difficult }\end{array}$} \\
\hline 6. To what extent has it been difficult to stand up from a chair? & mobility & \\
\hline 7. To what extent has it been difficult to walk inside the house? & mobility & \\
\hline 8. To what extent has it been difficult to put on and take off shirts? & self-care & \\
\hline 9. To what extent has it been difficult to put on and take off trousers and pants? & self-care & \\
\hline 10. To what extent has it been difficult to use the toilet? & self-care & \\
\hline 11. To what extent has it been difficult to wash your body in the bath? & self-care & \\
\hline 12. To what extent has it been difficult to go up and down stairs? & mobility & \\
\hline 13. To what extent has it been difficult to walk briskly? & mobility & \\
\hline 14. To what extent has it been difficult to keep yourself neat? & self-care & \\
\hline 15. How far can you keep walking without rest? (please select the closest answer) & mobility & $\begin{array}{l}\text { 0: more than } 2-3 \mathrm{~km} \\
\text { 1: approximately } 1 \mathrm{~km} \\
\text { 2: approximately } 300 \mathrm{~m} \\
\text { 3: approximately } 100 \mathrm{~m} \\
\text { 4: approximately } 10 \mathrm{~m}\end{array}$ \\
\hline 16. To what extent has it been difficult to go out to visit neighbors? & Interpersonal interactions & \multirow{6}{*}{$\begin{array}{l}\text { 0: not difficult } \\
\text { 1: mildly difficult } \\
\text { 2: moderately difficult } \\
\text { 3: considerably difficult } \\
\text { 4: extremely difficult }\end{array}$} \\
\hline $\begin{array}{l}\text { 17. To what extent has it been difficult to carry objects weighing approximately } \\
2 \mathrm{~kg}(2 \text { standard milk bottles or } 2 \text { PET bottles each containing } 1 \text { I)? }\end{array}$ & mobility & \\
\hline 18. To what extent has it been difficult to go out using public transportation? & mobility & \\
\hline $\begin{array}{l}\text { 19. To what extent have simple tasks and housework (preparing meals, } \\
\text { cleaning up, etc.) been difficult? }\end{array}$ & Domestic life & \\
\hline $\begin{array}{l}\text { 20. To what extent have load-bearing tasks and housework (cleaning the yard, } \\
\text { carrying heavy bedding, etc.) been difficult? }\end{array}$ & Domestic life & \\
\hline $\begin{array}{l}\text { 21. To what extent has it been difficult to perform sports activity } \\
\text { (jogging, swimming, gate ball, dancing, etc.)? }\end{array}$ & Community, social life & \\
\hline 22. Have you been restricted from meeting your friends? & Interpersonal interactions & \multirow{2}{*}{$\begin{array}{l}\text { 0: not restricted } \\
\text { 1: slightly restricted } \\
\text { 2: restricted about half the time } \\
\text { 3: considerably restricted } \\
\text { 4: gave up all activities }\end{array}$} \\
\hline $\begin{array}{l}\text { 23. Have you been restricted from joining social activities (meeting friends, } \\
\text { playing sport, engaging in activities and hobbies, etc.)? }\end{array}$ & Community, social life & \\
\hline 24. Have you ever felt anxious about falls in your house? & anxiety & \multirow{2}{*}{$\begin{array}{l}\text { 0: have not felt anxious } \\
\text { 1: have occasionally felt anxious } \\
\text { 2: have sometimes felt anxious } \\
\text { 3: have often felt anxious } \\
\text { 4: have constantly felt anxious }\end{array}$} \\
\hline 25. Have you ever felt anxious about being unable to walk in the future? & anxiety & \\
\hline
\end{tabular}

The question items in boldface are the daily activities selected in analysis of the frequency of poor response

From 25 question items, 4 regarding body pain and 2 regarding anxious feeling are omitted, and remaining 19 items provide response ratio (in bold letters) (This table is reused from our paper in Quality of Life Research under permission)

limitations relevant to the individual levels of ADL disability.

\section{Methods}

We used the data collected in a prospective cohort study on the disablement process of locomotive disability and development of guideline for locomotive disability prevention ("LDP study supported by a Sciences Research Grant from the Ministry of Health, Labor and Welfare, Japan (H21-Choju-G006)"). The participants joined outpatient rehabilitation programs at 5 facilities and were examined 4 times: at baseline and after 6,12 , and 18 months. We used the baseline data at the initial survey in this study. The detail of data 
collection for this cohort study was the same as that previously reported $[24,25]$.

\section{Participants}

Patients aged $\geq 65$ years $(N=314)$ were recruited from 5 orthopedic clinics and affiliated nursing care facilities which were located in 3 urban (Tokyo, Hamamatsu-shi, Hiroshima-shi) and 2 rural (Aizu Wakamatsu-shi, Nakatsu-shi) area. Written informed consent was obtained from all participants.

\section{Inclusion criteria}

1. Age $\geq 65$ years (either gender)

2. Any 1 of the following 4 criteria

1) Complaints related to the legs or spine without disability in walking or leaving the home (outpatients).

2) Complaints related to the legs and spine, and slight disabilities in walking and leaving the home (outpatients).

3) Slight disability in walking due to locomotive organ disorders (users of long-term care services).

4) Complaints related to the upper extremities without disability in walking or leaving the home (outpatients at orthopedic clinics).

3. Ability to answer the GLFS- 25 questionnaire without assistance.

4. Consent to radiographic examination of the knees and spine.

5. Consent to examination of the serum vitamin D and hyaluronic acid levels.

6. Consent to participate in the following motor function tests: one-leg standing test, measurements of grip power and leg extension power, 100-step test, and trunk forward bending test.

\section{Exclusion criteria}

1. Inability to stand up from a chair or bed.

2. Disability in walking or locomotion because of neurological disease requiring admission treatment.

3. Severe pulmonary, renal, coronary, or hepatic disease.

4. Mental illness.

5. Past history of stroke within the preceding 6 months.

6. Past history of myocardial infarction within the preceding 6 months.

7. Past history of fracture of a lower extremity within the preceding 6 months.

8. Current treatment for acute trauma.

9. Other reasons determined by the attending physician.

\section{Assessments}

Participants were asked about his or her history of falls and fractures, regular medications, diagnoses related to the locomotive organs, comorbidities, use of walking aids, living environment (especially number of family members needed for care), and physiotherapeutic interventions, and requested each participant to complete the GLFS-25 questionnaire.

The attending medical staff examined the patient based on the complaints and the specific painful area (back, buttock, posterior thigh, and knee), and recorded the physical findings related to the trunk and lower extremities. They also measured the body height, body weight, range of motion (ROM) of the hip and knee joints, and strength of the iliopsoas, quadriceps, anterior tibialis, and calf muscles, and recorded the results of the motor function tests, including the one-leg standing time, grip power, leg extension power, 100-step test, and trunk forward bending distance.

The staff obtained radiographs, including an anteroposterior view of the knee joints in a standing posture and a lateral view of the thoracolumbar spine, and assessed them quantitatively using semi-automated computer-aided diagnosis. The bone density of the wrist or metacarpal bones, the lumbar spine, or the proximal femur was measured using X-ray absorptiometry (DEXA), digital image processing (DIP), or quantitative computed tomography (QCT), and expressed as the percentage of the mean for young adults (YAM). Serum vitamin D and hyaluronic acid levels were also examined.

\section{Scale for assessing ADL ability: Geriatric Locomotive Function Scale-25}

The Geriatric Locomotive Function Scale-25 (GLFS-25) was originally developed to screen the persons with locomotive dysfunction. GLFS-25 included 4 questions regarding pain, 5 questions regarding self-care (put on and take off shirts and pants, wash body, use toilet and keep oneself neat), 8 questions regarding mobility (get up from bed and lie down, stand up from a chair, walk inside the home, go up and down stairs, walk briskly, keep walking, carry heavy object and use public transportation), 2 domestic life (simple housework and heavy housework), 2 community social life (join sports activity and social activity), 2 interpersonal interaction (visit neighbors and friends), and 2 anxiety (anxious about fall and inability of walk). Response choices to these 25 items are graded with 5-point scales: no impairment ( 0 points: Not difficult to do), mild impairment (1 points: mildly difficult to do), moderate impairment (2 points: moderately difficult to do), considerable impairment (3 points: considerably difficult to do) and severe 
impairment (4 points: extremely difficult to do) and then arithmetically added to produce a total score (minimum 0, maximum 100) (Table 1). The cut-off score for identifying Los was set at 16 on GLFS-25 total score [12]. Participants were asked to answer the GLFS-25 questions by themselves.

Responses to 19 items except pain and anxiety regarding daily activities were used to identify factors related to the severity of ADL disability and activity limitations relevant to the levels of ADL disability.

\section{Definition of poor responses, poor response ratio}

If participants reported no difficulty to do on a specific GLFS-25 question item, we considered the participant experienced no limitation in the activity represented by the question item. If participants reported mild, moderate, considerable or extreme difficulty (PR: Poor Response) to do on a certain GLFS25 question item, we considered the participant experienced activity limitation in the activity represented by the question item. Severity of activity limitation was assessed by response grades to GLFS-25 question items. If participants reported difficulties in more than one activity, we considered the participant experienced ADL disability. Poor Response Ratio (PRR) was calculated dividing the total number of group member by number of members who reported PR within each level of ADL disability.

\section{Analytic methods}

1) Classification of level of ADL disability. We converted the GLFS-25 scores into ordinal levels using "R language" program for optimal classification of histogram [26, 27], and designated the levels as the grades of ADL disabilities. ' $R$ ' is a free software programming language for statistical computing and graphics, and it is widely used among statisticians and data miners for statistical software development and data analysis.

2) Associations between numbers of activity limitations per participant and GLFS-25 levels To determine grades of ADL disability which participants experience, numbers of PRs (that is activity limitations) per person were compared among GLFS-25 levels using Kruskal-Wallis test followed by multiple comparison test by Bonferroni's correction. Level of significance was set at $<0.05$.

3) Associations between the GLFS-25 levels and severity of activity limitations

Jonckheere-Terpstra tests [28] were used to determine if there were statistically significant trend between the GLFS-25 levels on grade of responses to individual questions.
4) Frequency of activity limitation by the GLFS-25 level Poor response ratio for 19 daily activities was calculated within individual GLFS-25 levels in order to identify activity limitations which characterize ADL disability levels.

\section{Statistical analyses}

SPSS version 21 software (IBM, Chicago, IL, USA) was used for all statistical analyses. As variables showed nonnormal distribution, statistical analyses to test differences were performed using chi-square test and KruskalWallis test. Multiple comparison tests were performed using Bonferroni's correction. Significant levels were set at $p<0.05$ for KW tests and $p<0.0023$ for Bonferroni's tests. Jockheere-Terpstra test was used to determine if there were statistically significant trend between GLFS25 levels on differences of responses.

\section{Results}

\section{Descriptive characteristics of the participants}

Descriptive characteristics were shown in Table 2. Participants were 314 in number ( 80 men and 234 women) whose ages ranged from 65 to 93 years. The mean age was 75.9 years (Standard deviation SD: 6.3) in the men and 77.9 years (SD: 6.3) in the women. Mean of the GLFS-25 scores was 23.0 (SD: 15.8) ranged from 0 to 73. Numbers of physicians-diagnosed diseases for participants were as follows: knee osteoarthritis was diagnosed for 136 persons; osteoporosis 67, spinal canal stenosis 58, spinal spondylitis 54, and 133 participants had multiple diagnoses. Among this participant group, 268 participants had comorbidity, such as hypertension or diabetes, and 135 participants had multiple comorbidities. The number of participants with low back pain was 212 , with gluteal pain 94, with sciatic pain 44 , and with knee joint pain 203. The mean grip power was $20.8 \mathrm{~kg}$ (SD: 6.9), mean one-leg standing time was $17.5 \mathrm{~s}$ (SD: 19.6). The mean serum hyaluronic acid was $123.1 \mathrm{ng} / \mathrm{ml}$ (SD: 91.6), mean serum $25 \mathrm{OH}$ vitamin $\mathrm{D}$ was $44.7 \mathrm{ng} / \mathrm{ml}$ (SD: 22.2), mean bone mineral density was $78.2 \%$ YAM (SD: 17.8 ). One hundred and forty-three participants used walking aids, such as a stick or walkers. A history of falling was reported by 233 participants, and 158 had a history of fracture within the past few years.

\section{Classification of severity of ADL disability}

Using $\mathrm{R}$ language program, the GLFS-25 scores were stratified into seven groups as follows: $<6$, level $1 ; 7-15$, level 2 ; 16-22, level 3; 23-32, level 4; 33-40, level 5; 4149 , level 6 ; and $\geq 50$, level 7 . The number of the participants classified in the GLFS-25 level 1 was 36 , level 2 was 87 , level 3 was 68 , level 4 was 39 , level 5 was 31 , level 6 was 27 and level 7 was 22 . 
Table 2 Descriptive characteristics of participants

\begin{tabular}{|c|c|c|c|c|}
\hline \multirow[t]{2}{*}{ Gender } & & \multirow{2}{*}{$\begin{array}{l}\text { Male } \\
80\end{array}$} & \multirow{2}{*}{$\begin{array}{l}\text { Female } \\
234\end{array}$} & \multirow{2}{*}{$\begin{array}{l}\text { Total } \\
314\end{array}$} \\
\hline & & & & \\
\hline \multirow[t]{7}{*}{ Age } & mean & 75.9 & 77.9 & 77.4 \\
\hline & SD & 6.3 & 6.3 & 6.4 \\
\hline & $65-69$ & 19 & 33 & 52 \\
\hline & $70-74$ & 21 & 54 & 75 \\
\hline & $75-79$ & 17 & 56 & 73 \\
\hline & $80-84$ & 18 & 65 & 83 \\
\hline & 85- & 5 & 26 & 31 \\
\hline
\end{tabular}

Physicians-diagnosed locomotive disorders

$\begin{array}{llll}\text { Knee Osteoarthritis } & 28 & 108 & 136 \\ \text { Osteoporosis } & 0 & 67 & 67 \\ \text { Spinal Canal Stenosis } & 25 & 33 & 58 \\ \text { Degenerative Spondylosis } & 9 & 45 & 54 \\ \text { Low Back Pain } & 9 & 27 & 36 \\ \text { Joint diseases } & 11 & 16 & 27 \\ \text { vertebral fracture } & 1 & 18 & 19 \\ \text { Lower Limb fracture } & 3 & 15 & 18 \\ \text { Hip Osteoarthritis } & 0 & 10 & 10 \\ \text { Upper Limb fracture } & 1 & 8 & 9 \\ \text { Others } & 23 & 33 & 56\end{array}$

Number of locomotive disorders per participant

1
2
$3<$

$\begin{array}{lll}49 & 112 & 16 \\ 19 & 67 & 86 \\ 7 & 40 & 47\end{array}$

Comorbidity

$\begin{array}{llll}\text { Hypertension } & 47 & 127 & 174 \\ \text { Disorder of lipid metabolism } & 9 & 45 & 54 \\ \text { Cataract } & 9 & 37 & 46 \\ \text { Diabetes Mellitus } & 15 & 29 & 44 \\ \text { Cardiovascular diseases } & 11 & 33 & 44 \\ \text { Bronchial Asthma } & 4 & 7 & 11 \\ \text { Others } & 35 & 64 & 99\end{array}$

Number of comorbidities per participant

\begin{tabular}{|c|c|c|c|c|}
\hline & 0 & 9 & 37 & 46 \\
\hline & 1 & 33 & 100 & 133 \\
\hline & 2 & 22 & 62 & 84 \\
\hline & $\geqq 3$ & 16 & 35 & 51 \\
\hline Functional performance tests & mean & SD & range & median \\
\hline Leg extension power (kg) & 51.7 & 29.5 & $3.5-177.5$ & 47.5 \\
\hline One leg standing time with eyes open (sec) & 17.5 & 19.6 & $0-60$ & 9.1 \\
\hline Grip power (kg) & 20.8 & 6.9 & $6.0-44.0$ & 20.0 \\
\hline 100 steps time (sec) & 58.2 & 11.8 & $36.0-128.0$ & 56.0 \\
\hline Trunk forward bending distance $(\mathrm{cm})$ & 27.1 & 9.6 & $3.0-52.5$ & 28.5 \\
\hline
\end{tabular}


Table 2 Descriptive characteristics of participants (Continued)

\begin{tabular}{|c|c|c|c|c|}
\hline Laboratory findings & mean & SD & range & median \\
\hline Lumbosacral Angle (degree) & 30.9 & 19.1 & $-37.9-73.1$ & 32.4 \\
\hline Femorotibial Angle (degree) & 179.1 & 4.8 & $166.9-198.4$ & 178.3 \\
\hline Bone density; \%YAM & 78.2 & 17.5 & $40.0-166.0$ & 77.0 \\
\hline Hyaluronic Acid (ng/ml) & 124.6 & 103.1 & $15.2-800.0$ & 95.9 \\
\hline Vitamin D;25-OH D (ng/ml) & 46.1 & 22.4 & $7.0-145.0$ & 44.0 \\
\hline \multicolumn{3}{|c|}{ Numbers of participants with pain locations } & $\mathrm{N}$ & Prevalence (\%) \\
\hline & \multicolumn{2}{|l|}{ low back pain } & 212 & 76.5 \\
\hline & \multicolumn{2}{|l|}{ gluteal pain } & 94 & 27.3 \\
\hline & \multicolumn{2}{|l|}{ sciatic pain } & 44 & 14.9 \\
\hline & \multicolumn{2}{|l|}{ knee pain } & 203 & 64.6 \\
\hline \multicolumn{3}{|c|}{ Numbers of participants with limited joint movement } & N & Prevalence (\%) \\
\hline & \multicolumn{2}{|l|}{ hip } & 52 & 16.5 \\
\hline & \multicolumn{2}{|l|}{ knee } & 102 & 32.5 \\
\hline \multicolumn{3}{|c|}{ Number of participants whose muscles strength $>$ MMT 4} & $\mathrm{~N}$ & Prevalence (\%) \\
\hline & \multicolumn{2}{|l|}{ iliopsoas } & 220 & 70.1 \\
\hline & \multicolumn{2}{|l|}{ quadriceps } & 157 & 50.0 \\
\hline & \multicolumn{2}{|l|}{ anterior tibialis } & 87 & 27.7 \\
\hline \multicolumn{5}{|c|}{ Numbers of participant who received therapeutic exercise (with overlapping) } \\
\hline & \multicolumn{2}{|l|}{ therapeutic exercise } & & 184 \\
\hline & \multirow{3}{*}{\multicolumn{2}{|c|}{ muscle strengthening exercise }} & trunk muscles & 30 \\
\hline & & & quadriceps & 97 \\
\hline & & & mixed & 35 \\
\hline & \multicolumn{3}{|l|}{ balance training } & 17 \\
\hline & \multicolumn{3}{|l|}{ stretching } & 78 \\
\hline & \multicolumn{3}{|l|}{ other exercises } & 86 \\
\hline
\end{tabular}

Gender, age, diagnosis including comorbidity, results of functional performance tests and laboratory findings, signs and symptoms in lower extremities, and received therapeutic exercise are briefly summarized

\section{Association between numbers of activity limitation per participant and GLFS-25 levels}

Numbers of activity limitation per participant were determined by counting the number of PR. Mean number of activity limitation per participant was 9.1 (SD: 5.4. range: 0-19) for the whole.

Mean number of activity limitations per participant were 1.7 (SD: 1.4) for level 1 participants, 4.9 (SD: 1.7) for level 2, 9.1 (SD: 2.3) for level 3, 11.3(SD: 3.2) for level 4, 14.5 (SD: 2.9) for level 5, 15.9 (SD: 2.8) for level 6 and 17.4 (SD: 2.0) for level 7. The number of activity limitations was significantly related to the GLFS-25 levels (KW test: $p<0.002$ ) (Fig. 1).

Multiple comparison tests revealed significant differences between level 1 and 2, level 2 and 3, level 3 and 4, and level 4 and 5 (Bonferroni's correction: level of significance $p<0.0028$ ).

Table 3 showed mean numbers of individual response item per participant by GLFS-25 levels. The number of response 'not difficult' decreased in accordance with progression of ADL disability level. The number of 'mildly difficult' increased in accordance with progression of ADL disability levels 1-5, and was the greatest for the level 5 participants. The number of 'moderately difficult,' 'considerably difficult', and 'extremely difficult' were increased in accordance with progression of ADL disability level.

\section{Associations between the GLFS-25 levels and degree of difficulty on daily activities}

Jonckheere-Terpstra test rejected the null hypothesis that degrees of difficulty were equal between the GLFS25 levels by $p$ value $<0.001$ for 19 items regarding daily activities, which revealed significant aggregating trend between GLFS-25 levels on difficulty in doing daily activities (Fig. 2). It was revealed that the grade of difficulty in individual daily activity increased in accordance with the deterioration of ADL disability. 


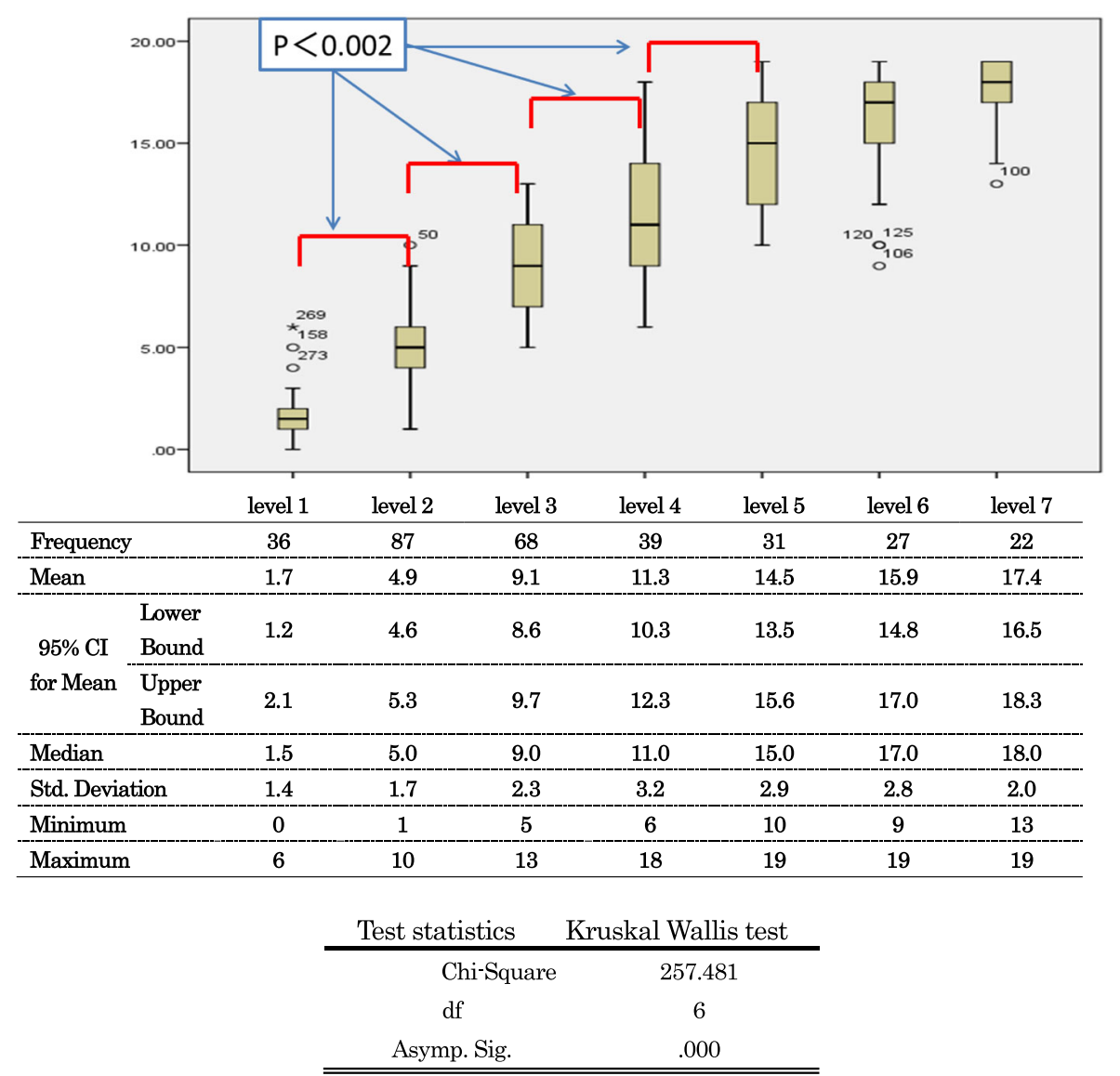

Fig. 1 Number of activity limitations of the GLFS-25 scores per participants by 7 levels. Test statistics on differences of item scores among the GLFS-25 total score levels. Kruskal Wallis tests and multiple comparison tests (Bonferroni's correction) (level of significance KW tests: $p<0.05$, Multiple comparison: $\mathrm{p}<0.0023)$. Participants in low GLFS-25 levels experienced smaller number of activity limitations than in higher GLFS-25 levels

\section{Frequency of poor response ratio (PRR) to questions regarding daily activities (Table 4)}

PRR corresponded to degree of difficulty on activities within GLFS-25 level and patterns of progression of disability.

In level 1, the $0 \%$ PRR was found in all but 2 question items ('join sports activity', 'join social activity'). In level 2, the $10 \%$ < PRR in 6 ('join sports activity', 'walk a long distance', 'join social activities', 'heavy housework', 'walk briskly', 'go up \& down stairs'). In level 3 , the $20 \%<$ PRR in
7 (those $10 \%$ < in level 2 plus 'carry heavy object'). In level 4 , the $20 \%<$ PRR in 9 (those $20 \%$ < in level 3 plus 'use public transportation', 'meet friends'). Its $50 \%<$ PRRs were more than half of 8 activities. In level 5 , the $50 \%<$ PRR in 6 (those $50 \%$ in level 4 plus 'walk a long distance'). In level 6 , the $50 \%<$ PRR in 8 (those $50 \%<$ in level 6 plus 'carry heavy object', 'use public transportation'). In level 7, the $50 \%<$ PRR in all but 4 items ('put on pants', 'walk indoors', 'use toilet', and 'put on shirts'). The $100 \%$ PRR were 'sports activity', 'walk briskly' and 'heavy housework'.

Table 3 Mean numbers of response items per participant by the GLFS-25 levels from 19 questions

\begin{tabular}{lllllllll}
\hline & Level 1 & Level 2 & Level 3 & Level 4 & Level 5 & Level 6 & Level 7 & Total \\
\hline Not difficult & 17.3 & 14.1 & 9.9 & 7.7 & 4.5 & 3.1 & 1.6 & 9.8 \\
Mildly difficult & 1.6 & 3.7 & 6.3 & 6.2 & 7.3 & 6.8 & 4.0 & 4.9 \\
Moderately difficult & 0.1 & 0.7 & 1.8 & 2.6 & 3.3 & 3.6 & 4.5 & 1.9 \\
Considerably difficult & 0.0 & 0.3 & 0.7 & 1.6 & 1.6 & 3.2 & 4.2 & 1.3 \\
Extremely difficult & 0.0 & 0.1 & 0.3 & 0.9 & 1.4 & 2.3 & 4.7 \\
\hline
\end{tabular}

The number of response 'not difficult' decreased and the number of 'moderately difficult', 'considerably difficult', and 'extremely difficult' were increased in accordance with progression of ADL disability level 


\section{Independent-Samples Jonckheere-Terpstra Test for Ordered Alternatives}

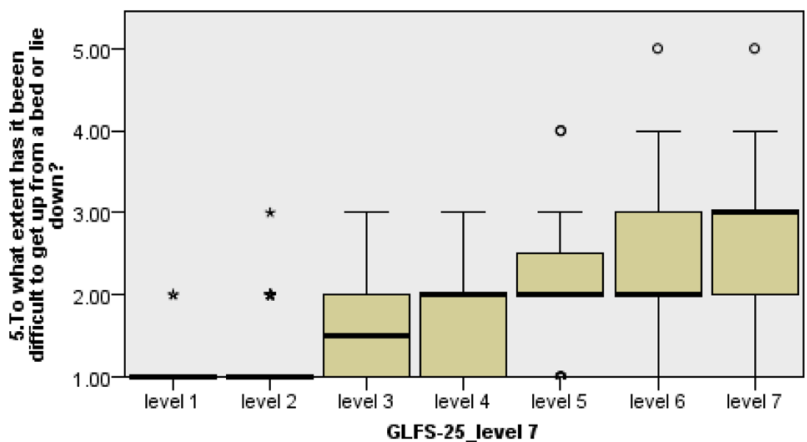

Test statistics

\begin{tabular}{lr}
\hline \multicolumn{1}{c}{ Total N } & 310 \\
\hline Test statistic & 28549.500 \\
Standard Error & 803.618 \\
Standardized Test Statistic & 10.976 \\
Asymp. Sig.(2-sided test) & 0.000 \\
\hline \hline
\end{tabular}

Fig. 2 An example result of Jonckheere-Terpstra test on question 'To what extent has it been difficult to get up from a bed or lie down?' Hypothesis that the distribution of response items is the same across categories of GLFS-25 level was rejected. The grade of difficulty in individual daily activity increased in accordance with the deterioration of ADL disability

Table 4 Poor response ratios for daily activities by the GLFS-25 levels

\begin{tabular}{|c|c|c|c|c|c|c|c|c|c|}
\hline Activities & $\begin{array}{l}\text { GLFS level } \\
\text { Ranges }\end{array}$ & $\begin{array}{l}\text { Level } 1 \\
-6\end{array}$ & $\begin{array}{l}\text { Level } 2 \\
7-15\end{array}$ & $\begin{array}{l}\text { Level } 3 \\
16-23\end{array}$ & $\begin{array}{l}\text { Level } 4 \\
24-32\end{array}$ & $\begin{array}{l}\text { Level } 5 \\
33-40\end{array}$ & $\begin{array}{l}\text { Level } 6 \\
41-49\end{array}$ & $\begin{array}{l}\text { Level } 7 \\
50-\end{array}$ & $\begin{array}{l}\text { Total } \\
0-73\end{array}$ \\
\hline (Question Items) & $\mathrm{N}$ & 36 & 87 & 68 & 39 & 31 & 27 & 22 & 311 \\
\hline 21.join sports activity & social activity & 5.6 & 28.7 & 58.8 & 76.9 & 90.3 & 100.0 & $100.0^{3}$ & 55.7 \\
\hline 23.join social activities & social activity & 5.6 & 18.4 & 26.5 & 51.3 & 67.7 & 66.7 & $77.3^{2}$ & 36.0 \\
\hline 13.walk briskly & locomotion & 0.0 & 10.3 & 39.7 & 66.7 & 87.1 & 92.6 & $100.0^{3}$ & 43.3 \\
\hline 12.go up \& down stairs & locomotion & 0.0 & 10.3 & 22.1 & 53.8 & 77.4 & 81.5 & $95.5^{3}$ & 35.7 \\
\hline 20.heavy housework & housework & 0.0 & 11.5 & 22.1 & 53.8 & 64.5 & 77.8 & $100.0^{3}$ & 34.7 \\
\hline 15.walk a long distance & locomotion & 0.0 & 23.0 & 44.1 & 48.7 & 67.7 & 85.2 & $95.5^{3}$ & 42.7 \\
\hline 17.carry heavy objects & housework & 0.0 & 9.2 & 25.0 & 43.6 & 48.4 & 59.3 & $95.5^{3}$ & 30.3 \\
\hline 18.use public transportation & locomotion & 0.0 & 2.3 & 7.4 & 23.1 & 45.2 & 55.6 & $95.5^{3}$ & 21.0 \\
\hline 6.stand up from chair & mobility & 0.0 & 0.0 & 7.4 & 10.3 & 19.4 & 44.4 & $77.3^{2}$ & 14.0 \\
\hline 5.get up from bed & mobility & 0.0 & 1.1 & 7.4 & 12.8 & 25.8 & 33.3 & $59.1^{2}$ & 13.1 \\
\hline 19.simple tasks & housework & 0.0 & 0.0 & 4.4 & 7.7 & 12.9 & 25.9 & $77.3^{2}$ & 10.8 \\
\hline 16.visit neighbors & keep company & 0.0 & 0.0 & 0.0 & 10.3 & 12.9 & 37.0 & $59.1^{2}$ & 9.9 \\
\hline 14.keep neat & self-care & 0.0 & 0.0 & 0.0 & 0.0 & 9.7 & 14.8 & $54.5^{2}$ & 6.1 \\
\hline 22.meet friends & keep company & 0.0 & 2.3 & 13.2 & 28.2 & 45.2 & 29.6 & $50.0^{1}$ & 17.8 \\
\hline 11.wash body & self-care & 0.0 & 0.0 & 0.0 & 7.7 & 12.9 & 29.6 & $50.0^{1}$ & 8.3 \\
\hline 9.put on pants & self-care & 0.0 & 0.0 & 0.0 & 7.7 & 12.9 & 37.0 & $45.5^{1}$ & 8.6 \\
\hline 7.walk indoors & mobility & 0.0 & 0.0 & 1.5 & 5.1 & 12.9 & 18.5 & $40.9^{1}$ & 6.7 \\
\hline 8.put on shirts & self-care & 0.0 & 2.3 & 1.5 & 0.0 & 9.7 & 14.8 & $31.8^{1}$ & 5.4 \\
\hline 10.use toilet & self-care & 0.0 & 0.0 & 0.0 & 2.6 & 3.2 & 7.4 & $36.4^{1}$ & 3.8 \\
\hline \multicolumn{2}{|c|}{ number of the items with PRR $50 \%<$} & 0 & 0 & 1 & 5 & 6 & 8 & 15 & \\
\hline
\end{tabular}

The frequency of activity limitations was increased level by level in accordance with the progression of ADL disabilities except 'put on shirts' and 'use toilet' Aligned PRR on all participants in descending order

Nineteen items in the level 7 divided into 3 groups which are indicated by superscript 1-3 
We identified 3 groups of activities characterized by the level of PRR in level 7. (Table 4).

Group 1: Activities with mild difficulty: 6 activities (4 regarding self-care, 1 mobility, and 1 interpersonal interaction). Less than half of the participants reported difficulties for the 6 activities.

Group 2: Activities with moderate difficulty: 6 activities: 2 regarding mobility, 1 domestic life, 1 social life and 1 interpersonal interaction. More than half (50-80\%) of the participants reported difficulties for the 6 activities.

Group 3: Activities with severe difficulty: 7 activities: 4 regarding mobility, 2 domestic life, 1 social life. Almost all of the participants reported difficulties for the 7 activities.

Activities included in group 1 were considered the easiest to perform, and those in included in group 3 the hardest. The groups of activities were suggestive of hierarchical order of activity limitations.

These present results showed both increasing number of activity limitation and progression of severity in difficulty in activities were significantly related to the levels of ADL disability. The results also showed difficulties in mobility appeared in less severe level, difficulties in domestic and social life appeared in moderately severe level, and difficulties in self-care appeared in advanced level.

\section{Discussion}

Participants of this study were elderly people with locomotive disorders and they reported difficulties in basic and instrumental ADL. Mean GLFS-25 score (23.0, and SD 15.8) indicated participants were satisfied criteria for identifying persons with LoS. The participants were considered to be fitted to the people who were in the condition corresponded to the concept of Locomotive syndrome [7].

Disability in ADL is an adverse outcome of frailty that places a burden on elderly people, families, care providers, and the care system [29]. Frailty is defined as a state of increased vulnerability to poor resolution of homeostasis after stress or events [30]. Frailty is a heterogeneous condition consisting of symptoms which do not attribute specifically to a certain organ.

Physical frailty and cognitive frailty were defined as special forms of frailty. Physical frailty is a special form of frailty defined as a medical syndrome with multiple causes and contributors that is characterized by diminished strength, endurance, and reduced physiologic function that increases an individual's vulnerability for developing increased dependency and/or death [31]. Another specific form of frailty, cognitive frailty, was proposed as a new clinical condition with coexisting physical frailty and cognitive impairment in nondemented older subjects [32].
LoS is one of the potential causes of physical frailty and locomotive organ-targeted state which developed to aim at controlling the increase in elderly people requiring assistance from others (LTCI care needs). The reasons why we newly introduce LoS as specific form of physical frailty are association of pain problems and multiple involvements in locomotive organs requiring medical treatments or care supports.

Although physical impairments and declined motor ability were proved to relate to the GLFS-25 score, examination on the characteristics of disability (numbers and severity of activity limitations, corresponding to the GLFS-25 total score) was not sufficient. Studies to determine risk factors or predictors of LoS were conducted using the GLFS-25 [13-20]. However those previous studies did not provide insight into ADL disability. Identification of factors related to severity of ADL disability is necessary to develop intervention program to prevent or slow down aggravation of ADL disability.

The results from present study showed significant relationships of disability level with the number and severity of activity limitation. The findings suggested that aggravation of ADL disability level is associated with increase of numbers of activity limitations and deterioration of difficulty in executing activities.

Iwaya, Doi and Akai [20] reported that the prevalence of persons reported difficulty was high in walking related activities ('walk briskly', 'walk a long distance', 'go up and down stairs') and low in self-care activities ('put on pants', 'use toilet', 'take a bath') in people with mild level of ADL disability, and the prevalence was high in both activities in advanced level of disability. In the present study, we suggested hierarchical order of activity limitations in progression of disability. The hierarchical order was consistent with those reported previous articles [33-35].

Older adults who are disabled can recover from a disabled state [36]. To reduce numbers of activity limitation and/or ameliorate difficulty in daily activities may contribute recovery from disability.

In mild disability level (level 2-4), frequency of activity limitations was high in mobility related activities, and low in self-care related activities. In the advanced level (level 5-7) frequency of activity limitations was high in both mobility and self-care related activities. These findings suggested difficulties in mobility related activities, particularly walking related activities, may be ahead of ADL disability in elderly people with locomotive disorders. Lawrence and Jett [37] described that lower extremity functional limitation was a stronger predictor of disability than upper extremity. Shinkai et al. [38] reported walking speed as a good predictor for the onset of functional dependence, defined as a new disability in one or more of the five basic activities of daily living, or 
death of a subject who had shown no disability at the previous follow-up in a Japanese rural community population.

Findings from present study revealed that people with mild ADL disability experienced difficulties of mild degree in mobility activity and people with advanced ADL disability experienced difficulties of moderate to severe degree in mobility activity and difficulties of mild degree of self-care activities. According to the findings, we assume that physical exercise to restore walking capacity such as aerobic exercise or strengthening exercise of lower leg muscles are efficient to prevent deterioration of ADL disability for people in level 2 and 3. Interventions to reduce difficulties in self-care activities may benefit people in level 4 and over. Those interventions include not only physical exercise such as ROM exercise, stretching, but using aids or devices, personal assistance and accommodation of living conditions.

Two types of disability are distinguished, namely progressive and catastrophic disability [39]. Progressive disability develops with older age in association with underlying diseases, comorbidity and frailty and resulted from physical functional decline. Disabilities develop abruptly (sudden onset) or insidiously and progress step by step. Catastrophic disability is the result of an acute clinical event such as hip fracture or stroke. In elderly people disability may begin abruptly in cases of hip fractures, may progress slowly such as in cases of LoS and may suddenly deteriorate following accidental events such as fall or pneumonia or death of spouse.

Progressive disability may take years to make elderly people disabled. There may be people without functional limitations who have impairment, and people without disability who have functional limitations. Identification of people without disability who have functional limitations and people without functional limitations who have impairments allows for appropriate approach at different points in the disablement pathway [40]. Similarly, identification of people with mild disability and with severe disability allows for appropriate approach at different points in deterioration process of disability.

\section{Limitation of the present study}

Because this study used cross-sectional data, there are several limitations. Findings that number and severity of activity limitations significantly related to severity of disability are suggestive of pattern of progression of disability. Disabilities develop with time and the processes are dynamic by nature. The applicability of the patterns of disability progression should be verified in longitudinal survey data. The hierarchic model presented in this article is also hypothetical and need to be tested in a longitudinal study.
Concept of LoS is not satisfactory operationalized and characteristics of LoS are not well described at present time. Further studies on disablement process describing progression from locomotive organ disorders (degenerative arthritis, osteoporosis, sarcopenia) to impairment (pain on lumbar spine and lower extremity, ROM limitation, muscle weakness) to functional limitation (slow walking speed, weak muscle strength, reduced flexibility) and disability (difficulties experienced during doing familiar tasks) are needed to develop strategies for prevention and restoration of disabilities resulting from locomotive organ disorders.

\section{Conclusions}

Participants with higher GLFS-25 score reported larger numbers of activity limitations of greater degree of difficulty. High GLFS-25 score represented high degree of ADL disability. Disability may deteriorate in accordance with increase of numbers and aggravation of activity limitation. Activity limitation may occur in the following order: sports activity, walking, transferring, and self-care.

\section{Abbreviations \\ \% YAM: \% young adults mean; ADL: Activity of daily living; DEXA: Dual-energy X-ray absorptiometry; GLFS -25: Geriatric Locomotive Function Scale - 25; LoS: Locomotive syndrome; LTCl: Long-Term Care Insurance; PRR: Poor response ratio; QCT: Quantitative computed tomography; ROM: Range of motion; SD: Standard deviation}

\section{Acknowledgements}

We wish to thank Keiji Fujino, Mahito Kawashima, Masahito Honda, Eiji Hatano, Hirohiko Inanami for their cooperation in collecting data. We are also grateful to all of the orthopedic surgeons, their staff members, and those who willingly participated in this study (5 study sites): Fujino Orthopaedic Clinic in Hamamatsu-shi,

Kawashima Orthopaedic Hospital in Nakatsu-shi, Takeda General Hospital in Aizu Wakamatsu-shi,

Hatano Rehabilitation and Orthopaedic Clinic in Hiroshima-shi, Iwai Orthopaedic and Medical Hospital in Tokyo.

\section{Funding}

This study was supported by a Sciences Research Grant (H21-Choju-G-006) from the Ministry of Health, Labor, and Welfare, Japan. Recipient: Tsutomu Iwaya.

\section{Availability of data and materials}

The datasets generated during and/or analyzed during the current study are available from the corresponding author on reasonable request.

\section{Authors' contributions}

TI conceived and designed the study; AS, YO, and TO performed the study and collected the data; TD, TI, and MA performed statistical analysis of the data and interpreted the results; TI and MA wrote the article; All authors read and approved the final manuscript.

\section{Ethics approval and consent to participate}

All procedures performed in studies involving human participants were in accordance with the ethical standards of the institutional and/or national research regulations, and with the 1964 Helsinki declaration and its later amendments or comparable ethical standards.

Written informed consent was obtained from all participants, and all study protocols were approved by the institutional review board of the National Rehabilitation Center for Persons with Disabilities (No. 21-77). 


\section{Consent for publication}

Not applicable.

\section{Competing interests}

No benefits in any form have been or will be received from any commercial party related directly or indirectly to the subjects of this article. The authors declare that they have no competing interest to disclose.

The correspondence, Masami Akai, is a member of the editorial board (Associate Editor) of BMC geriatrics.

\section{Publisher's Note}

Springer Nature remains neutral with regard to jurisdictional claims in published maps and institutional affiliations.

\begin{abstract}
Author details
${ }^{1}$ Nagano University of Health and Medicine, 11-1 Imaihara Kawanajima-chou Nagano-shi, Nagano 381-2227, Japan. ${ }^{2}$ Geriatric Care Facilities Excellent Care Shizu, 1316-1 Kami-Shizu, Sakura, Chiba 285-0846, Japan. ${ }^{3}$ Mitsui Memorial Hospital, 1 Kanda-Izumi-chou, Chiyoda-ku, Tokyo 101-0024, Japan. ${ }^{4}$ Tochigi Rehabilitation Center, 3337-1 Komanyu-machi, Utsunomiya, Tochigi 320-8503, Japan. ${ }^{5}$ National Rehabilitation Center for Persons with Disabilities, 4-1 Namiki, Tokorozawa, Saitama 359-8555, Japan. ${ }^{6}$ International University of Health and Welfare, 4F, Aoyama 1-Chome Tower, 1-3-3 Minami-Aoyama, Minato-ku, Tokyo 107-0062, Japan.
\end{abstract}

\section{Received: 6 February 2017 Accepted: 10 July 2017}

Published online: 26 July 2017

\section{References}

1. Cabinet Office, Government of Japan. White paper on the Aging Society. 2016. http://www8.cao.go.jp/kourei/whitepaper/w-2016/zenbun/pdf/1s1s_1.pdf Accessed 12 Dec, 2016.

2. Arai H, Ouchi Y, Toba K, Endo T, Shimokado K, Tsubota K, et al. Japan as the front-runner of super-aged societies: perspectives from medicine and medical care in Japan. Geriatr Gerontol Int. 2015;15(6):673-87.

3. Ministry of Health, Labour and Welfare. Annual Report on the Long-term Care Insurance. 2013. http://www.mhlw.go.jp/topics/kaigo/osirase/jigyo/13/ dl/h25_point.pdf Accessed 12 Dec, 2016.

4. Ministry of Health, Labour and Welfare. Current State and Trends on the Elderly and their Environment. 2015. http://www8.cao.go.jp/kourei/english/ annualreport/2015/pdf/c1-2-1.pdf Accessed 12 Dec 2016.

5. Ministry of Health, Labour and Welfare. Comprehensive Survey of Living Conditions. Table 16. (in Japanese) 2010. http://www.e-stat.go.jp/SG1/estat/ List.do?lid=000001083953 Accessed 12 Dec. 2016.

6. Ministry of Health, Labour and Welfare. Comprehensive Survey of Living Conditions. Table 18. (in Japanese) 2013. http://www.e-stat.go.jp/SG1/estat/ List.do?lid=000001119740 Accessed 12 Dec 2016.

7. Nakamura K. Locomotive syndrome: disability-free life expectancy and locomotive organ health in a "super-aged" society. J Orthop Sci. 2009;14(1):1-2.

8. Nakamura K, Ogata T. Locomotive syndrome: definition and management. Clin Rev Bone Miner Metab. 2016;14:56-67.

9. Seichi A, Kimura A, Konno S, Yabuki S. Epidemiologic survey of locomotive syndrome in Japan. J Orthop Sci. 2016;21(2):222-5.

10. Yoshimura N, Nakamura K. Epidemiology of locomotive organ disorders and symptoms: an estimation using the population-based cohorts in Japan. Clin Rev Bone Miner Metab. 2016;14:68-73.

11. Japanese Orthopaedic Association. Pamphlet of Locomotive Syndrome. (in Japanese) 2015. https://locomo-joa.jp/news/upload_images/locomo_ pf2015.pdf Accessed 12 Dec 2016

12. Seichi A, Hoshino Y, Doi T, Akai M, Tobimatsu Y, Iwaya T. Development of a screening tool for risk of locomotive syndrome in the elderly: the 25-question geriatric locomotive function scale. J Orthop Sci. 2012;17(2):163-72.

13. Ogata $T$, Muranaga $S$, Ishibashi $H$, Ohe T, Izumida R, Yoshimura N, et al. Development of a screening program to assess motor function in the adult population: a cross-sectional observational study. J Orthop Sci. 2015;20(5):888-95.

14. lizuka Y, lizuka H, Mieda T, Tajika T, Yamamoto A, Takagishi K. Populationbased study of the association of osteoporosis and chronic musculoskeletal pain and locomotive syndrome: the Katashina study. J Orthop Sci. 2015;20(6):1085-9.
15. Muramoto A, Imagama S, Ito Z, Hirano K, Ishiguro N, Hasegawa Y. Physical performance tests are useful for evaluating and monitoring the severity of locomotive syndrome. J Orthop Sci. 2012;17(6):782-8.

16. Muramoto A, Imagama S, Ito Z, Hirano K, Tauchi R, Ishiguro N, et al. Waist circumference is associated with locomotive syndrome in elderly females. J Orthop Sci. 2014;19(4):612-9.

17. Muramoto A, Imagama S, Ito Z, Hirano K, Ishiguro N, Hasegawa Y. Spinal sagittal balance substantially influences locomotive syndrome and physical performance in community-living middle-aged and elderly women. J Orthop Sci. 2016;21(2):216-21.

18. Muramoto A, Imagama S, Ito Z, Hirano K, Tauchi R, Ishiguro N, et al. Threshold values of physical performance tests for locomotive syndrome. J Orthop Sci. 2013;18(4):618-26.

19. Seichi A, Hoshino Y, Doi T, Akai M, Tobimatsu Y, Kita K, et al. Determination of the optimal cutoff time to use when screening elderly people for locomotive syndrome using the one-leg standing test (with eyes open). J Orthop Sci. 2014;19(4):620-6.

20. Iwaya T, Akai M, Doi T. Clinical picture of locomotive syndrome with disabilities in elderly people. (in Japanese) J Jpn Orthop Assoc. 2015;89(5): 365-72.

21. Tobimatsu Y. Locomotive syndrome: its clinical features and aggravation process. (in Japanese) Bone Joint Nerve. 2014; 4(3): 467-72.

22. Tsutsui T, Muramatsu N. Care-needs certification in the long-term care insurance system of Japan. J Am Geriatr Soc. 2005;53(3):522-7.

23. Iwaya T, Doi T, Seichi A, Hoshino Y, Ogata T, Akai M. Relationship between physician-judged functioning level and self-reported disabilities in elderly people with locomotive disorders. Qual Life Res. 2017;26(1):35-43.

24. Iwaya T, Doi T, Nakamura K, Akai M, Tobimatsu Y, Hoshino Y, et al. Operational definition of Locomotive syndrome. (in Japanese) J Jpn Orthop Assoc. 2014; 88(10): 731-8.

25. Akai M, Doi T, Seichi A, Okuma Y, Ogata T, Iwaya T. Locomotive syndrome: operational definition based on a questionnaire, and exercise interventions on mobility dysfunction in elderly people. Clin Rev Bone Miner Metab. 2016;14:119-30.

26. Aoki S. Transforming continuous variable data into categorical data with $\mathrm{R}$ language. (in Japanese) 2006. http://aoki2.si.gunma-u.ac/R/recode.html Accessed 12 Dec 2016.

27. Aoki S. Search for optimal classification of the histogram using Akaike Information Criterion. (in Japanese) 2007. http://aoki2.si.gunma-u.ac.jp/R/AICHistogram.html Accessed 12 Dec 2016.

28. The Jonckheere-Terpstra test using SPSS Statistics. https://statistics.laerd. com/spss-tutorials/jonckheere-terpstra-test-using-spss-statistics.php Accessed 12 Dec 2016.

29. Vermeulen J, Neyens JCL, van Rossum E, Spreeuwenberg MD, de Witte LP. Predicting ADL disability in community-dwelling elderly people using physical frailty indicators: a systematic review. BMC Geriatr. 2011;11:33.

30. Clegg A, Young J, lliffe S, Rikkert MO, Rockwood K. Frailty in elderly people. Lancet. 2013;381(9868):752-62.

31. Morley JE, Vellas B, van Kan GA, Anker SD, Bauer JM, Bernabei R, et al. Frailty consensus: a call to action. J Am Med Dir Assoc. 2013;14(6):392-7.

32. Kelaiditi E, Cesari M, Canevelli M, van Kan GA, Ousset PJ, Gillette-Guyonnet S, et al. Cognitive frailty: rational and definition from an (IANA/IAGG) international consensus group. J Nutr Health Aging. 2013;17(9):726-34.

33. Kempen GIJM, Suurmeijer TPBM. The development of a hierarchical polychotomous ADL-IADL scale for noninstitutionalized elders. Gerontologist. 1990;30(4):497-502.

34. Dunlop DD, Hughes SL, Manheim LM. Disability in activities of daily living: patterns of change and a hierarchy of disability. Am J Public Health. 1997:87(3):378-83.

35. Ferrucci L, Guralnik JM, Cecchi F, Marchionni N, Salani B, Kasper J, et al. Constant hierarchic patterns of physical functioning across seven populations in five countries. Gerontologist. 1998;38(3):286-94.

36. Hardy SE, Dubin JA, Holford TR, Gill TM. Transitions between states of disability and independence among older persons. Am J Epidemiol. 2005;161(6):575-84.

37. Lawrence $\mathrm{RH}$, Jette AM. Disentangling the disablement process. J Gerontol B Psychol Sci Soc Sci. 1996;51(4):S173-82.

38. Shinkai S, Watanabe S, Kumagai S, Fujiwara Y, Amano H, Yoshida H, et al. Walking speed as a good predictor for the onset of functional dependence in a Japanese rural community population. Age Ageing. 2000;29(5):441-6. 
39. Ferrucci L, Guralnik JM, Simonsick E, Salive ME, Corti C, Langlois J. Progressive versus catastrophic disability: a longitudinal view of the disablement process. J Gerontol A Biol Sci Med Sci. 1996;51(3):M123-30.

40. Guralnik JM, Ferrucci $L$. The challenge of understanding the disablement process in older persons: commentary responding to Jette AM. Toward a common language of disablement. J Gerontol A Biol Sci Med Sci. 2009;64(11):1169-71.

Submit your next manuscript to BioMed Central and we will help you at every step:

- We accept pre-submission inquiries

- Our selector tool helps you to find the most relevant journal

- We provide round the clock customer support

- Convenient online submission

- Thorough peer review

- Inclusion in PubMed and all major indexing services

- Maximum visibility for your research

Submit your manuscript at www.biomedcentral.com/submit 